\title{
COMPARING THE PERSONAL LIVES OF PSYCHOTHERAPISTS AND RESEARCH PSYCHOLOGISTS
}

\author{
DISSERTATION
}

\author{
Presented to the Graduate Council of the \\ University of North Texas in Partial \\ Fulfillment of the Requirements
}

\author{
For the Degree of \\ DOCTOR OF PHILOSOPHY
}

By

JoAnn Taylor Radeke, B.A.

Denton, Texas

December, 1997 
Radeke, JoAnn Taylor, Comparing the personal lives of psychotherapists and research psychologists. Doctor of Philosophy (Clinical Psychology), December 1997, 77 pp., 12 tables, references, 30 titles.

Although the personal life of the therapist has been a topic of interest for nearly sixty years there is still a paucity of research in this area. There is also a lack of research into the personal lives of researcher psychologists. In this study 282 psychologists (151 researchers and 131 therapists) who attended regional meetings and seminars sponsored by professional psychological associations in Texas were sampled. Job stressors, personal problems and health concerns, relaxation techniques, life satisfaction, and work impact on personal life were some of the areas examined. The most important stressors associated with research were excessive teaching responsibilities, pressures associated with funding and lack of time for a personal life. For therapists the most important stressors associated with work were suicide attempts by clients, clients showing resistance, and clients being angry. Therapists 
reported more concerns related to anxiety, depression, and family problems than researchers. Both groups chose exercise/sports and movies/television as their most common methods for relaxation. Therapists were three times more likely to have been in therapy than researchers and once in therapy reported six times the number of hours. Researchers reported less childhood abuse than therapists. However, therapists were more satisfied with their current life, indicating having good friends and liking where they lived more than researchers. Therapists were also more likely to feel that their work had impacted their lives and that these benefits were mostly positive. The array of positive benefits ranged from being a better person to enjoying life more. Overall, results showed that, although therapists generally began life in less happy circumstances, and experienced greater personal problems and health concerns currently, they reported feeling more satisfied with their lives than researchers. 


\title{
COMPARING THE PERSONAL LIVES OF PSYCHOTHERAPISTS AND RESEARCH PSYCHOLOGISTS
}

\author{
DISSERTATION
}

\author{
Presented to the Graduate Council of the \\ University of North Texas in Partial \\ Fulfillment of the Requirements
}

\author{
For the Degree of \\ DOCTOR OF PHILOSOPHY
}

By

JoAnn Taylor Radeke, B.A.

Denton, Texas

December, 1997 


\section{ACKNOWLEDGMENTS}

It is with enormous gratitude that I extend my heartfelt thanks to Michael J. Mahoney. His help and guidance have been instrumental from the inception to the completion of this project. As a graduate student and as a person, I am lucky to have him as a mentor and a friend.

Special acknowledgment goes to my husband of twenty-five years, Tom. Thank you for your support and encouragement. This would not have been possible without all the personal sacrifices, both emotional and financial, that you have made in order to support my efforts.

Last, but certainly not least, I am indebted to every psychologist who took the time to complete one of my surveys. I sincerely thank you for your time and effort. 


\section{TABLE OF CONTENTS}

\section{Page}

LIST OF TABLES $\ldots \ldots \ldots \ldots \ldots \ldots \ldots \ldots \ldots \ldots \ldots \ldots \ldots \ldots \ldots$

Chapter

1. INTRODUCTION $\ldots \ldots \ldots \ldots \ldots \ldots \ldots \ldots \ldots \ldots \ldots \ldots$

Personal Lives of Psychologists

Personal Lives of Researchers

Personal Lives of Therapists

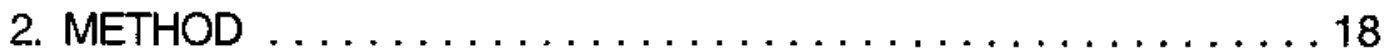

Subjects

Materials

Procedure

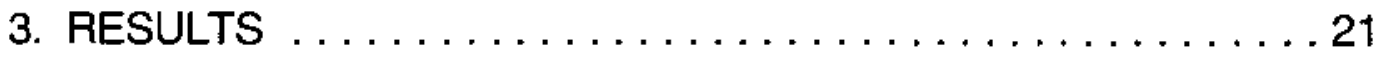

Descriptive Statistics

Common Sources of Job Stress

Personal Problems and Health Concerns

Relaxation Techniques

Childhood Happiness and Abuse

Life Satisfaction

Personal Therapy

Impact of Work on Personal Lives

4. DISCUSSION ........................ 39

Introduction 
Common Sources of Job Stress

Personal Problems and Health Concerns

Relaxation Techniques

Childhood Happiness and Abuse

Life Satisfaction

Personal Therapy

Impact of Work on Personal Lives

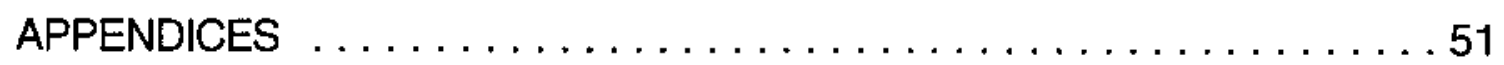

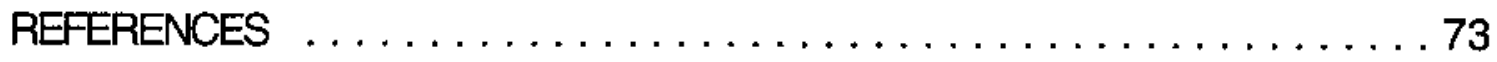




\section{LIST OF TABLES}

Table

Page

1. Researcher Current Theoretical Orientation $\ldots \ldots \ldots \ldots 61$

2. Therapist Current Theoretical Orientation . . . . . . . . 62

3. Researcher Rankings of Job Stressors $\ldots \ldots \ldots \ldots \ldots \ldots 63$

4. Therapist Rankings of Job Stressors $\ldots \ldots \ldots \ldots \ldots \ldots 64$

5. Researcher Rankings of Personal Problems and Health

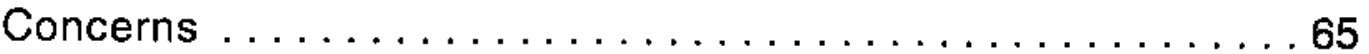

6. Therapist Rankings of Personal Problems and Health

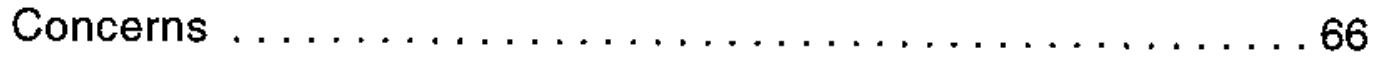

7. Researcher Rankings of Forms of Relaxation $\ldots \ldots \ldots \ldots 67$

8. Therapist Rankings of Forms of Relaxation $\ldots \ldots \ldots \ldots 68$

9. Research Life Satisfaction Variables .............69

10. Therapist Life Satisfaction Variables $\ldots \ldots \ldots \ldots \ldots \ldots 70$

11. Researcher Reports of Work Impact on Personal Life . . . . . 71

12. Therapist Reports of Work Impact on Personal Life . . . . 72 


\section{CHAPTER 1}

\section{INTRODUCTION}

\section{Personal Lives of Psychologists}

The personal life of the psychotherapist has been a topic of interest and speculation almost since the inception of psychoanalysis in 1895 (Guy, 1987; Kottler, 1990). It was sixty years ago that Freud (1937/1964) first commented on the dangers analysis posed for the analyst. Despite this warning, little research has been done regarding the impact of conducting psychotherapy on the personal life and relationships of the therapist. As it has been noted that therapists' personalities change as they conduct psychotherapy, it seems reasonable to assume that conducting psychotherapy has a noticeable effect on the therapist's personal relationships and life (Guy, 1987). Kottler (1990) writes that the greatest benefits of practicing therapy are the daily lessons therapists learn. He notes that each client brings in the sum of their accumulated knowledge and then proceeds to share this with 
the therapist. In this manner therapists are offered an intimate glimpse into the world of others. The work of psychotherapists involves many facets of the their being. As Otto Will (as cited in Guy, 1987) noted, "the personality of the therapist will inevitably be involved and exposed in such an undertaking: there is no way whereby one can keep oneself as a person, detached from the therapeutic process, nor should there be" (p. 563).

The person of the therapist and the personal life of the therapist have been recognized as important since the beginning of the field. This connection is why Freud recommended training analysis for analysts. Evidence has also accumulated over the last thirty years of research on psychotherapy process and outcome (Bergin \& Garfield, 1994). This evidence makes clear that the person of the psychotherapist contributes more to psychotherapy outcome than was believed earlier in the century. Therefore the person and personal life of the psychotherapist take on greater importance as factors to understand in terms of the conducting of psychotherapy. There is also research (Mahoney \& Fernandez-Alvarez, 1995) that suggests that the psychological development of service providers in psychology may be substantially accelerated by their work. This would suggest the possibility that since the change process seems 
to be amplified and accelerated in therapists that studying their personal lives and development may be a particularly fruitful path for studying change processes in general.

Research on the Personal Life of the Therapist

Early research established a small data base of information about psychologists. In general these early surveys focused on obtaining basic demographic information (Henry, Sims, \& Spray, 1971). Later research focused on how the psychologists' personal lives and personalities influenced their work (Garfield \& Bergin, 1978). Clinical psychologists and their professional orientations and attitudes were also surveyed, this time with the emphasis on their professional lives (Garfield \& Kurtz, 1974, 1975a, 1975b; Kelly, 1961; Norcross \& Prochaska, 1982a, 1982b, 1982c). These surveys pointed out that psychologists were shifting the emphasis of their activities from diagnostic testing to psychotherapy during the 1950's (Kelly, 1961), as well as the diversity of clinicians and the popularity of eclecticism during the 1960's and early 1970's (Garfield \& Kurtz, 1974, 1975a, 1975b). One result of note was the relatively small percentage of time clinical psychologists devoted to research activities. Only $52.8 \%$ of clinicians were involved in any research, and of that group only $7.9 \%$ of their time was spent in 
research activities (Norcross \& Prochaska, 1982a). This finding replicated earlier findings by Garfield and Kurtz $(1974 ; 1976)$ and Kelly (1961). Henry, Sims and Spray (1973) also noted that most therapists adopted a unidimensional attitude toward all their relationships, whether they be with clients, friends, or family. Kottler (1990) called this a "distancing aura" in which the clinician detached not only from therapeutic encounters but from home life and professional societies as well. Other research reported that relationshop problems, depression and substance abuse are not uncommon problems for practitioners to experience (Elliott \& Guy, 1993; Thoreson, Miller \& Krauskopf, 1989).

There was still a need for research in the area of how psychologists' work affects their personal lives. Research by Prochaska and Norcross (1983) narrowed the representative sample to American psychologists engaged in psychotherapy. Their survey focused on therapists' work related activities and showed that the psychodynamic orientation was experiencing renewed preference, therapists spent relatively small percentages of their time doing research $(3.9 \%)$, and over $80 \%$ had personal therapy and valued this experience as preparation for becoming human service providers. 
In 1983, Farber surveyed a sample of 60 psychotherapists to determine the effects of psychotherapeutic practice on them and to assess their perceptions of the interface between their personal and professional lives. According to these therapists, therapeutic work had three major consequences: (1) $60.4 \%$ stated that they believed they had become more psychologically-minded, (2) $58.5 \%$ thought their therapeutic work had raised personal issues and provided increased introspection, and (3) $20.8 \%$ felt that their self-esteem and self-confidence had been enhanced by their therapeutic work. In this study the effects were generally in a positive direction and were consistent with the types of changes therapists seek to promote in their clients.

Farber (1983) believed that those who become clinicians seemed to possess a psychological-mindedness in childhood, experiencing the world in a more introspective way. He proposed that this psychological-mindedness during childhood prepared and facilitated their choice of psychology as a profession. This tendency toward heightened awareness was then reinforced by years of participation in a "psychological" world as a student, patient, and psychotherapist. Ultimately, this framework was the primary means 
of ordering their world, both professionally and personally and did not come with an easy on-off switch (Farber, 1983).

In an exploratory study, Deutsch (1985) collected basic selfreport data on personal problems and treatment among psychotherapists. His results showed that over half of the 264 therapists surveyed had experienced relationship difficulties or depression. Master's-level therapists and agency employees were more likely than other groups to have experienced depression. Forty-seven percent of all subjects had sought therapy at one time in their lives for relationship problems, and female therapists were more likely than males to have sought therapy for relationship concerns and depression. Those working in agencies revealed more of a reluctance to seek therapy than those in private practice. Therapists serving agencies were more likely to have considered therapy for personal problems but less likely to have followed through.

Farber (1985) published research examining clinical psychologists' perceptions of psychotherapeutic work. This study investigated the satisfactions and stresses of clinical psychologists who were performing psychotherapeutic work and used an expanded data base (members of the clinical psychology division of a large 
state psychological association). This study was also designed to assess feelings of burnout and which demographic and/or workrelated variables had the strongest effect on psychologists' experience of psychotherapeutic work.

Based on this research (Farber, 1985) it appeared that clinical psychologists were focusing more on the satisfying aspects of their work than on the stressful aspects. There was a moderate but significant relationship between experience level and stress, indicating that therapeutic work was most stressful for inexperienced therapists. This corroborated previous research (Farber \& Heifetz, 1981). Therapists appeared confident in their abilities to be helpful and empathic and were gratified by their work and committed to staying in the field. These results were also consistent with a survey by Norcross and Prochaska (1982c), whose data indicated that clinical psychologists were satisfied with their careers and that a career change was unlikely for $90 \%$ of their survey. In Farber's (1985) study clinical psychologists seemed considerably less vulnerable to burnout than other human service professionals (e.g., policemen, teachers, nurses) and private practitioners were significantly less at risk for burnout than those whose work was institutionally based or who had split practices. 
Collegial relationships appeared to be a key factor in preventing burnout among this group. For those psychologists who were institutionally based there was significantly less of "a real sense of community" among staff members. Farber's findings were relatively consistent with Norcross and Prochaska's (1982a, 1982b, 1982c) national survey. However, both of these studies conflicted with Sarason's (1981) claim that many psychologists were disillusioned with the field. While often cited, this claim was based on anecdotal and autobiographical evidence. It is interesting to note that no empirically based study was done to substantiate his claim.

In clarifying the sources of stress in psychotherapeutic work, Hellman and Morrison (1987) found that psychologists whose caseloads were comprised of a substantial proportion of characterdisorder or psychotic patients reported more work-related stress. Psychologists in institutional settings reported more stress from work-related issues due primarily to significantly greater feelings of personal depletion and tendencies to become more over involved in their work.

In 1985, Farber found that clinical psychologists seemed fulfilled and gratified by their work and professional relationships. Most (94 - 98\%) reported being relatively unaffected by burnout. His 
results were based on a relatively experienced sample of clinical psychologists who were psychodynamically-oriented and who practiced in the same state. He concluded that Sarason's (1981) claim that many psychologists had become disillusioned with the field was not corroborated by this sample. Farber's (1985) research showed that clinical psychologists in general and those practicing in private settings were generally enjoying their work a great deal. $\mathrm{He}$ was particularly interested in the finding that increasing levels of clinical experience were associated with reduced vulnerability to the stresses of therapeutic work.

Although sparse, some research suggests that mental health professionals often come from families where they experienced emotional distress as children. In 1993, Elliott and Guy conducted research focusing on the childhood family environments of women mental health workers compared with women working in other professions. Their research suggested that families of mental health workers were often dysfunctional and these women experienced significant psychological distress in adult life (Elliott \& Guy, 1993). Mental health professionals reported higher rates of physical abuse, sexual molestation, parental alcoholism, psychiatric hospitalization of a parent, death of a family member and greater 
family dysfunction in their families of origin than did other professionals surveyed. However, as adults, female psychotherapists experienced less anxiety, depression, dissociation, sleep disturbance, and impairment in interpersonal relationships than did women in professions other than mental health (Elliott \& Guy, 1993).

Recent research has focused on how the work life of the psychologist affects his or her personal life (Mahoney, 1991, 1997). Mahoney (1997) surveyed 155 mental health practitioners regarding their personal problems and concerns. His study noted that the most common problems clustered around emotional exhaustion and fatigue. Feelings of isolation, disillusionment about the profession, interpersonal relationships, anxiety, and depression were also reported. The least frequent complaints were somatic and substance abuse problems. In responding to concerns about alcohol use, there was a significant gender-related difference with male practitioners reporting a greater concern than females. A large majority $(87.7 \%)$ of participants reported having had some personal psychotherapy, with women reporting more frequency and longer duration than men. Also of note was the significant gender difference in reports of having been a client within the past year. In this study $46.5 \%$ of the 
female participants reported having had personal therapy within the year as compared with only $27.9 \%$ of the males (Mahoney, 1997).

Although this study corroborated previous studies indicating that mental health practitioners do experience personal problems, the data suggested that they may be less troubled and unhappy than had been indicated by some previous investigations. Pleasure reading, physical exercise, hobbies, and recreational vacations were the most frequently reported methods of self-care. Four out of five of the respondents reported reading for pleasure, taking pleasure trips or vacations, engaging in a hobby, attending movies, visiting museums or attending artistic events. Physical exercise was reported by three out of four respondents as a self-care method and almost as many reported using peers for feedback and support (Mahoney, 1997). This emerging area of research answers some questions, but raises others.

Research on the Personal Life of the Research Psychologist Although the data base about the personal lives of psychotherapists is small it is well-documented when compared to the dearth of research done on the research psychologist. The Socratic imperative, "Know thyself," is sadly forgotten in the case of the psychologist who labors in research. 
Boice and Myers (1987) reported research that suggested that, when compared to psychotherapists, academicians experience higher levels of job-related stresses and concerns. Freudenburger (1986) found that psychologists employed in institutional and academic settings often confront stressors such as bureaucracy and the pressures of high productivity expectations. Boice and Myers (1987) found that in addition to higher levels of job-related stress, healthrelated stress and mental health problems were experienced at higher rates by academicians than by private practitioners. Some of the primary contributors to this stress were: low salaries, high levels of committee work and paperwork, concern about colleagues' misbehavior, lack of professional recognition, worry over incomplete projects, problems with insomnia, and thoroughness in work beyond the point of effectiveness. This would suggest that the world of the researcher is not one of total happiness cloistered in the ivory tower of academia, but an arena with pressures to produce and publish, or perish.

This brief summary is the extent of what has been done to document the life of the research psychologist. Obviously further research in this area would be helpful. 
Rationale

The primary purpose of this study was to compare several aspects of the personal and job lives of research psychologists and psychotherapists. While both groups have small data bases currently, it is clear that much less is known about the personal life of the research psychologist. Some trends had been noted in research concerning psychotherapists and the data were examined to determine if similar trends existed for research psychologists. Direct comparisons were made, where appropriate, to determine if there were significant differences between the two groups.

In addition to comparing the two groups, this study was designed to add to the current data bases and to contribute to knowledge of these divisions within psychology. In the past there has been some equivocation regarding the degree to which psychotherapists experience personal problems. While some earlier work made it appear that, as a group, psychotherapists were rather unhappy (Sarason, 1981), more recent research indicates that they are a fairly happy lot (Farber, 1983, 1985; Mahoney, 1991, 1997). It was expected that this study would corroborate more recent research indicating a higher degree of satisfaction. 
Opinions regarding personal therapy are of particular interest as well. Although research has suggested that most psychotherapists have engaged in personal therapy (Mahoney, 1997), the extent to which researchers avail themselves of this service is currently unknown. It was predicted that this number would be significantly lower for researchers than for psychotherapists.

Although there are many questions worthy of asking, this study limited its focus to the following seven areas of concern. It should be noted that, within each area, significant differences were examined to determine if they were related to gender or years of experience:

(1) What are common sources of job stress within each group? A checklist of job stressors related to each career (researchers and therapists) was completed. Participants were then asked to rank order the checked items according to their most important concerns during the past year. No prediction was made concerning this area. (2) Are there differences in the personal problems and health concerns of the two groups? Again, a checklist was used with respondents rank ordering their choices. There was no basis in the literature for saying therapists' personal problems and health concerns were different from researchers (Elliott \& Guy, 1993). 
Although no prediction was made regarding differences between the two groups, some gender differences were predicted on this item. Literature suggested that males in general would report more concerns about their use of alcohol (Mahoney, 1997). Literature also suggested that females would report higher levels of abuse as a child (Elliott \& Guy, 1993).

(3) Are there differences in how the two groups seek relaxation? A checklist and ranking was utilized for this question as well. It was predicted that there would be no difference in how the two groups sought relaxation.

(4) Is there a difference between the two groups in childhood happiness? Participants were asked to check items that applied to them. One of the items was the statement "I was happy as a child". Based on research by Guy (1987) and Elliott and Guy (1993), it was predicted that there would be a significant difference with therapists reporting less happy childhoods than researchers. (5) Is there a difference in levels of life satisfaction among therapists and researchers? A checklist of items referring to ones' personal life was used, the subitems related to positive effects were tallied and a score given for overall life satisfaction. It was 
predicted that therapists would report significantly greater degrees of life satisfaction than researchers.

(6) Are there differences in the two groups' experience of personal therapy? Respondents were asked to list the number of hours of personal therapy and the number of different therapists they had seen. Then they were asked to complete a survey of four questions referring to experiences in therapy. The questions were presented in a 4-point Likert-type response format in which " 1 " indicated "disagree" and "4" indicated "agree. It was expected that three significant differences would be found:

(a) therapists would be more likely to have been in therapy than researchers,

(b) therapists would be likely to have more hours of therapy than researchers,

(c) therapists would be more likely to have seen more therapists than researchers (Mahoney \& Fernandez-Alvarez, 1995).

(7) Are there differences in the impact of their work on their personal lives? This was assessed via a series of statements presented in a 4-point Likert-type response format in which "1" indicated "strongly disagree" and " 4 " indicated "strongly agree". Each statement referred to the effects of work either as a 
psychotherapist or researcher on the individual's personal life (Appendix A). Research by Guy (1987) and Mahoney (1991) led to the prediction that there would be significant group differences, with therapists agreeing more often with the following statements:

(a) has made me a better person,

(b) has increased my self-awareness,

(c) has accelerated my psychological development,

(d) has sometimes felt like a form of spiritual service,

(e) has increased my capacity to detach from my feelings,

(f) has made me more tolerant of ambiguity,

(g) has resulted in changes in my value system.

On this question it was also hypothesized that there would be differences associated with levels of experience in the therapist group only. As years of experience increased, it was expected that therapists would report the following statements significantly more often:

(a) has increased my self-awareness,

(b) has increased my psychological development,

(c) has made me a better person,

(d) has made me a wiser person,

(e) has sometimes felt like a form of spiritual service. 


\section{CHAPTER 2}

\section{METHOD}

Subjects

Subjects consisted of 276 psychologists, drawn from two areas within the field. The sample of researchers was of psychologists who identified themselves as engaged primarily in research activities (research psychologists). The researcher sample consisted of 146 respondents $(21.2 \%$ female and $75.3 \%$ male $)$ The other sample consisted of psychologists who identified themselves as being engaged primarily in delivering psychotherapy services (therapists). Psychologists who were not able to identify themselves as belonging primarily to one group or the other were eliminated from the survey. The therapist sample consisted of 130 respondents $(56.2 \%$ female and $42.3 \%$ male).

\section{Materials}

A self-report questionnaire developed by Mahoney (1997) was the survey instrument used. The original instrument, Therapist's 
Personal Life Questionnaire (TPLQ) was modified to create a second questionnaire for research psychologists (Research Psychologist's Personal Life Questionnaire - RPPLQ) (Appendix A). Both instruments requested basic demographic information as well as information on health concerns, problems encountered in the work environment, self-care strategies, opinions regarding personal therapy, and the perceived effects of career on their personal lives. Some items were presented with a 4-point Likert-type response format in which "1" indicated "strongly disagree" and "4" indicated "strongly agree." Other items were presented in a format allowing the participant to indicate which items applied to them (example: checking all personal and health concerns that apply out of a list of 22) and then rank ordering the checked items $(1,2,3)$ with "1" meaning "most important", etc. A cover letter addressed to the sample (researchers or therapists) was attached to each survey (Appendix A). This letter served to introduce the author, briefly explained the research, and fulfilled the obligations of informed consent.

\section{Procedure}

These two page surveys along with the attached cover letter were distributed to psychologists (mostly research psychologists) 
attending a regional psychological convention of the Southwestern Psychological Association in San Antonio, Texas on April 13th, 14th, and 15th of 1995. Participants were asked to complete surveys as they entered a poster session area. The survey was given to psychotherapists in a similar fashion at several events advertised in newsletters of the Dallas Psychological Association or the Texas Psychological Association. Surveys were completed by participants in a seminar on hypnosis on May 19, 1995 in Dallas. The event was advertised in the Dallas Psychological Association Newsletter. Another event where the surveys were completed was at a workshop entitled "Marketing Your Private Practice II," sponsored by the Dallas Psychological Association on June 9, 1995. The majority of the surveys, however, were completed by participants at the Texas Psychological Association 1995 Spring Conference in New Orleans on June 2nd and June 3rd. The participants at each of these events were psychologists who identified themselves as psychotherapists. 


\section{CHAPTER 3}

\section{RESULTS}

This chapter is divided into several sections and subsections.

Descriptive statistics and each area of concern is given a section.

These sections are: (1) sources of job stress, (2) personal problems and health concerns, (3) relaxation, (4) childhood happiness and abuse, (5) life satisfaction, (6) personal therapy, and (7) impact of work on personal life. Each of these sections is then divided into subsections: (1) information regarding researchers, (2) information regarding therapists and, where appropriate, a section for (3) comparing researchers' and therapists' responses. When participants were asked to rank order checklists of their job stressors, health problems and concerns, and relaxation techniques, an overall ranking of items on each checklist is reported.

\section{Descriptive Statistics}

Questionnaires were completed by 282 psychologists (151 researchers and 131 therapists). A total of six surveys were 
excluded from the data analyses. Of this number five were from researchers and one was from a therapist. Reasons for exclusion were failure to complete the second page of the survey (3), lack of experience (they indicated zero as years of experience in their field) (2), and one respondent indicated an equal amount of time spent in research and in therapy work.

The remaining 276 surveys consisted of 146 researchers $(21.2 \%$ female and $75.3 \%$ male) and 130 therapists $(56.2 \%$ female and $42.3 \%$ male). The age range for researchers was from 25 years to 78 years $($ mean $=43.7$, median $=44$, mode $=50$ ). The number of years of experience for researchers ranged from 1 year to 40 years with a mean of 13.8 years of experience. Of those researchers reporting a current theoretical orientation $(69.9 \%)$, the primary theoretical orientations were experimental/research $(24.6 \%)$, cognitive $(9.6 \%)$, integrative/eclectic $(7.5 \%)$, behavioral $(5.5 \%)$, and social $(4.8 \%)$. (see Table 1).

Therapists in the sample ranged in age from 23 years to 80 years ( mean $=45.9$, median $=46$, mode $=40)$. The number of years of experience for therapists ranged from 1 year to 40 years with a mean of 12.78 years of experience. Of therapists who indicated a current theoretical orientation $(80 \%)$, the primary theoretical 
orientations were integrative/eclectic (29.2\%), psychodynamic $(17.7 \%)$, cognitive behavioral $(12.3 \%$ ), and systems $(6.9 \%)$ (see Table 2).

\section{Common Sources of Stress}

\section{Researchers}

The most frequently reported stressors for researchers were: pressures associated with funding $(58.2 \%)$, lack of time for a personal life $(54.1 \%)$, bureaucratic problems $(53.4 \%)$, poor quality peer reviews $(47.9 \%)$, excessive teaching responsibilities $(44.5 \%)$, excessive paperwork (43.8\%), and excessive committee responsibilities $(43.2 \%)$. Job stressors that were reported least frequently by researchers were lack of new ideas $(8.9 \%)$, feeling overwhelmed by pace of change $(8.9 \%)$, and restrictions on freedom of inquiry $(8.9 \%)$. When researchers were asked to rank these items according to their most important concerns during the past year they. were ranked as follows: (1) excessive teaching responsibilities $(30.8 \%)$, (2) pressures associated with funding $(28.8 \%)$, (3) lack of time for personal life $(27.4 \%)$, (4) bureaucratic problems $(26.8 \%)$, and (5) excessive committee responsibilities (22.6\%) (see Table 3). There were statistically significant differences associated with level of experience and the items excessive committee 
responsibilities $(\underline{r}=.295, \underline{p}=.01)$, poor quality peer reviews $(\underline{r}=$ $.273, p=.01)$, and excessive paperwork $(r=.218 . p=.01)$. There were no statistically significant differences associated with gender.

\section{Therapists}

The most frequently endorsed concerns for therapists were:

clients showing resistance $(96.2 \%)$, clients being angry $(95.4 \%)$, suicide attempts by clients $(85.4 \%)$, panic attacks in clients $(83.8 \%)$, paranoid behavior by clients $(82.3 \%)$, and premature termination by clients $(82.3 \%)$. The only job stressor reported by less than 10 percent of the therapists was clients suing them $(6.2 \%)$. When therapists were asked to rank these items according to their most important concerns during the past year they were ranked as follows: (1) suicide attempts by clients $(43.9 \%)$, (2) clients showing resistance $(30.1 \%)$, (3) clients being angry $(25.4 \%)$, (4) premature termination by clients $(21.5 \%)$, (5) paranoid behavior by clients (19.3\%), and (5) clients becoming dependent on the therapist (19.3\%) (See Table 4). There were no statistically significant differences associated with gender. Statistically significant differences were associated with levels of experience and clients refusing to pay for 
services $(\underline{r}=.376, \underline{p}=.01)$, clients being seductive $(\underline{r}=.284, \underline{p}=.01)$, and death of a client (but not by suicide) $(\underline{r}=.262, \underline{p}=.01)$.

\section{Personal Problems and Health Concerns}

\section{Researchers}

The most frequently reported personal problems and health concerns for researchers were: financial security $(36.3 \%)$, relationship problems $(34.2 \%)$, sleep problems $(28.1 \%)$, depression (27.4\%), and shyness (27.4\%). Anorexia and schizophrenia were the least reported problems $(1.4 \%$ and $0 \%$, respectively). When asked to rank these items according to their most important concerns during the past year they were ranked as follows: (1) financial security $(19.9 \%),(2)$ relationship problems $(18.5 \%),(3)$ sleep problems $(17.8 \%),(4)$ low self-confidence $(15 \%)$, and (5) shyness $(14.4 \%)$ (see Table 5). Only eight percent of researchers reported concerns regarding alcohol use. There was a statistically significant difference associated with gender on the item emotional exhaustion $\left(X^{2}(1)=13.83, \underline{p}=.0002\right)$, with females more likely to report feeling emotionally exhausted. A Bonferroni correction reduced the alpha level to $p=.002$. There was a statistically significant difference associated with level of experience and being overweight $(r=.263, p$ $=.01)$. 


\section{Therapists}

The most frequently reported personal problems and health concerns for therapists were: low self-confidence $(53.8 \%)$, anxiety $(52.3 \%)$, depression $(48.5 \%)$, relationship problems $(47.7 \%)$, and emotional exhaustion (46.9\%). As with researchers, anorexia and schizophrenia were the least reported problems $(1.5 \%$ and $0 \%$, respectively). When asked to rank these items according to their most important concerns during the past year, therapists ranked them as follows: (1) emotional exhaustion (27.7\%), (2) anxiety $(23.9 \%)$, (2) financial security $(23.9 \%)$, (4) being overweight $(20 \%)$, and (5) sleep problems (18.5\%), depression (18.5\%), and low selfconfidence $(18.5 \%$ ) (see Table 6). Nine percent of therapists reported concerns regarding alcohol abuse. There were no statistically significant differences associated with gender. There was a statistically significant difference associated with level of experience and poor health $(\underline{r}=.234, \underline{p}=.01)$.

\section{Comparison}

When comparing researchers and therapists on reported personal problems and health concerns, therapists reported concerns related to anxiety $\left(X^{2}(1)=31.76, p<.001\right)$ and depression $\left(X^{2}(1)=13.04, p=\right.$ .0003) more often than did researchers. They also reported concerns 
regarding low self-esteem $\left(X^{2}(1)=16.12, \underline{p}<.001\right)$ and low selfconfidence $\left(X^{2}(1)=24.77, \underline{p}<.001\right)$ more often than did researchers. Family problems were reported more often by therapists $\left(X^{2}(1)=\right.$ $19.42, \underline{p}<.001)$ as was emotional exhaustion $\left(X^{2}(1)=17.02, \underline{p}<\right.$ .001). A Bonferroni correction for the above analyses reduced the alpha level to $\underline{p}=.0023$. When comparing researchers and therapists on the question of reported alcohol abuse, no statistically significant difference was obtained.

Relaxation

\section{Researchers}

The most frequently endorsed activities for relaxation for researchers were: exercise/sports $(74.6 \%)$, movies/television $(70.4 \%)$, music $(56.3 \%)$, and pleasure reading $(54.2 \%)$. Massage $(3.5 \%)$ and stretching $(6.3 \%)$ were the least common mode of relaxation chosen by researchers. When asked to rank these previously checked items according to their most frequent choices they were ranked as follows: (1) exercise/sports (47.2\%), (2) movies/television $(38.1 \%)$, (3) pleasure reading $(33.9 \%)$, (4) music $(28.9 \%)$, and (5) socializing with friends $(24.7 \%$ ) (see Table 7 ). There were statistically significant differences associated with gender in this area on the 
use of massage and socializing with friends, with females reporting more frequent use of massage $\left(X^{2}(1)=18.35, \underline{p}<.001\right)$ and socializing with friends $\left(X^{2}(1)=9.03, p=.003\right)$ as a form of relaxation. A Bonferroni correction reduced the alpha level to $p=$ .00357.) There were no statistically significant differences associated with level of experience.

\section{Therapists}

The most frequently endorsed activities for relaxation among therapists were: movies/television ( $84.4 \%)$, exercise/sports $(80.5 \%)$, socializing with friends $(74.2 \%)$, music $(71.9 \%)$, and pleasure reading $(70.3 \%)$. When asked to rank these items according to their most frequent choices therapists ranked them as follows:

(1) exercise/sports (43\%), (2) movies/television (38.3\%), (3) pleasure reading $(35.2 \%)$, (4) socializing with friends $(32.1 \%)$, and (5) meditation/prayer (24.2\%) (see Table 8). There were no statistically significant differences in this realm associated with gender or level of experience.

Comparison

Therapists were more likely to engage in meditation/prayer $\left(X^{2}(1)=36.67, \underline{p}<.001\right)$, massage $\left(X^{2}(1)=37.27, \underline{p}<.001\right)$, and 
stretching $\left(X^{2}(1)=11.65, \underline{p}=.00064\right)$ than were researchers.

Therapists were also much more likely to engage in socializing with friends than researchers $\left(X^{2}(1)=16.67, \underline{p}=.00004\right)$. A Bonferroni correction for the above analyses reduced alpha to $\mathrm{p}=.0036$. There were no differences associated with gender of levels of experience within the research or therapist sample in this realm.

Childhood Happiness and Abuse

\section{Researchers}

Roughly three out of four researchers (76\%) reported having had a happy childhood, with only $2.7 \%$ indicating childhood abuse. There were no statistically significant differences associated with gender or level of experience in the area of childhood happiness or abuse.

\section{Therapists}

Sixty-one percent of therapists reported having had a happy childhood, with $18.5 \%$ reporting having been abused as a child. There were no statistically significant differences associated with gender or level of experience in these realms.

\section{Comparison}

In comparing therapists and researchers on childhood happiness another significant difference was encountered $\left(X^{2}(1)=7.46, \underline{p}=\right.$ 
.006), with researchers being more likely than therapists to report having had a happy childhood. However, when individuals who reported childhood abuse were partialled out of the analysis, there was no significant difference between therapists and researchers on the question of childhood happiness. On this question (childhood happiness) there were no gender differences within the research or therapist samples, respectively. There were no statistically significant differences in this realm associated with level of experience.

When comparing researchers and therapists on the question of childhood abuse a significant result was obtained, $\left(X^{2}(1)=18.65, \underline{p}=\right.$ .00002), with therapists endorsing "I was abused as a child" at a rate six times greater than the rate of researchers. On this question there were no gender differences within the research or therapist samples, respectively. However, when looking at the question of possible gender differences in childhood abuse across both samples, a statistically significant result was encountered $\left(X^{2}(1)=11.23, p=\right.$ .0008 ), with females in the study more than three times more likely to have endorsed this item than males (18\% and $5 \%$, respectively). 


\section{Life Satisfaction}

\section{Researchers}

This sample of researchers and therapists appeared to be a happy group. Researchers described themselves as happy (88\%) and healthy $(87 \%)$. They reported liking their work $(92 \%)$, liking themselves $(90 \%)$, and indicated that they had good friends $(81 \%)$. The lowest levels of satisfaction for this group were associated with liking where they live $(67 \%)$ and liking their body $(62 \%)$ (see Table 9 ). There were no statistically significant differences associated with gender or levels of experience.

\section{Therapists}

Therapists also described themselves as happy (92\%) and healthy $(94 \%)$ and having good friends $(92 \%)$. They reported liking their work $(92 \%)$, liking themselves $(95 \%)$, and liking where they lived $(83 \%)$.

The lowest level of satisfaction for this sample was in liking their bodies $(65 \%)$ (see Table 10). There were no statistically significant differences associated with gender or levels of experience.

\section{Comparison}

Therapists reported having good friends and liking where they lived more often than did researchers $\left(X^{2}(1)=6.51, \underline{p}=.01 ; X^{2}(1)=\right.$ $9.25, \underline{p}=.002$, respectively). 
In order to compare overall life satisfaction, a composite variable was created by summing the number positive items respondents checked (question $\# 8$, items $1,2,3,4,6,7$, and 8 ). In comparing therapists and researchers on overall life satisfaction a significant result was obtained $(\underline{t}(273)=2.57, \underline{p}=.011)$ with therapists reporting higher levels of life satisfaction $(\underline{M}=6.12, \underline{S D}=$ 1.28) than researchers $(\underline{M}=5.68, \underline{S D}=1.54)$. Results of analyses for internal consistency of the items on the life satisfaction variable were in the acceptable range (alpha $=.68$; alpha $=.66$, for researchers and therapists, respectively). In this realm there were no differences associated with gender or levels of experience within the research or therapist sample.

\section{Personal Therapy}

Respondents were asked to list the number of hours of personal therapy and the number of different therapists they had seen. They were then asked to complete a survey of four questions referring to experiences in therapy. The questions were presented in a 4-point Likert-type response format in which "1" indicated "disagree" and "4" indicated "agree". Responses on either side of the midpoint were collapsed for analysis purposes and in order to report simple percentages of agreement. 


\section{Researchers}

Twenty-five percent of researchers reported having experienced some personal therapy. Although $90 \%$ felt that therapy had been a valuable experience, one-third reported having had some negative experiences. Twenty-four percent felt embarrassed about their need for therapy, while $42 \%$ reported some concern about the financial cost of therapy. There were no statistically significant differences associated with gender or level of experience on questions relating to the value of therapy, negative experiences in therapy, embarrassment about needing therapy or the cost of therapy.

\section{Therapists}

Seventy percent of the therapists in this sample had been in personal therapy. Ninety-six percent of those reported that therapy had been a valuable experience, but $28 \%$ reported having had some negative experiences. Nineteen percent of therapists who had been in therapy reported being embarrassed about needing therapy. Concern about the financial cost of therapy was a problem for $34 \%$. In the sample of therapists there were no statistically significant differences associated with gender or level of experience on questions relating to the value of therapy, negative experiences in 
therapy, embarrassment about needing therapy or the cost of therapy.

\section{Comparison}

In comparing researchers and therapists on the question of number of hours of personal therapy a significant difference was obtained $(\underline{t}(274)=3.49, \underline{p}=.001)$, with therapists reporting more hours of personal therapy $(\underline{M}=98.57, \underline{S D}=248.75)$ than researchers $(\underline{M}=16.11, \underline{S D}=110.14)$. On the number of different therapists seen, there was also a significant difference $(\underline{t}(89.86)=2.72$, $\underline{\mathrm{p}}$ $.008)$, with therapists $(\underline{M}=2.31, \underline{S D}=1.26)$ having seen a significantly greater number of therapists than researchers $(\underline{M}=$ $1.71, \underline{S D}=1.14)$

There were no statistically significant differences between researchers and therapists on questions relating to the value of therapy, negative experiences in therapy, embarrassment about needing therapy or the cost of therapy. There were also no statistically significant differences associated with theoretical orientation in this realm.

\section{Impact of Work on Personal Lives}

This question used a four point Likert format $(1=$ disagree, $4=$ agree). Responses on either side of the midpoint were collapsed for 
analysis purposes and in order to report simple percentages of agreement.

\section{$\underline{\text { Researchers }}$}

A small majority of researchers $(67.8 \%)$ reported that their work had influenced their personal lives. The five most commonly reported effects for researchers, in descending order, were: (1) had made them wiser people $(80.8 \%),(2)$ had made them better people $(78.1 \%),(3)$ had made them more respectful of individual differences (69.1), (4) had increased their self-awareness (68.5\%) and, (5) had accelerated their psychological development (68.5\%) (see Table 11). One out of four researchers reported that their work had sometimes felt like a form of spiritual service, had increased their capacity to detach from their feelings, and/or had made them more pessimistic about human nature. Roughly $38 \%$ of researchers reported that their work had resulted in changes in their value system, while $37 \%$ reported that they sometimes doubted the value of research. There were no statistically significant differences associated with gender or level of experience on these questions.

\section{Therapists}

A majority of therapists $(90 \%)$ indicated that their work had influenced their personal life. The five most commonly reported 
effects for therapists, in descending order, were: (1) had made them a better person $(93.9 \%)$, (2) had made them more respectful of individual differences $(93.9 \%)$, (3) had increased their selfawareness $(92.3 \%)$, (4) had made them wiser people $(92.3 \%)$, and (5) had increased their appreciation for human relationships $(90.0 \%)$ (see Table 12). Three out of four therapists indicated that their work had sometimes felt like a form of spiritual service, while $40 \%$ reported that they sometimes doubted the value of therapy. One out of four therapists felt their work had made them more pessimistic about human nature. A small majority indicated that their work had increased their capacity to detach from their feelings. Sixty-one percent of therapists reported that their work had resulted in changes in their value system. There were no statistically significant differences associated with gender or level of experience in this realm.

Comparison

In reporting the comparison for each of the following statements regarding the effect of work on their personal lives, a Bonferroni correction reduced alpha levels to $\underline{p}=.0025$. Only those comparisons that were statistically significant at that alpha level are reported. 
In reporting the effects of their work on their personal lives, researchers were much more likely than were therapists to indicate that their work had no effect on their personal lives $\left(X^{2}(1)=21.77\right.$, $<.001)$. More often than did their research counterparts, therapists felt their work had made them better people $\left(X^{2}(1)=11.48, p=\right.$ $.001)$, wiser people $\left(X^{2}(1)=12.94, \mathrm{p}<.001\right)$, and had increased their self-awareness $\left(X^{2}(1)=22.90, \underline{p}<.001\right)$ more often than researchers. Therapists were also more likely than researchers to feel that their job had accelerated their psychological development $\left(X^{2}(1)=13.91, \mathrm{p}<.001\right)$, made them more tolerant of ambiguity $\left(X^{2}(1)=10.77, \underline{p}=.001\right)$, and increased their capacity to detach from their feelings $\left(X^{2}(1)=26.57, p<.001\right)$. Relative to researchers, therapists were also more likely to report that their work had increased their appreciation for human relationships $\left(X^{2}(1)=39.89\right.$, $\mathrm{p}<.001$ ) and made them more respectful of individual differences $\left(X^{2}(1)=23.32, p<.001\right)$. Therapists were also more likely to feel that their work had helped increase their capacity to enjoy life $\left(X^{2}(1)=15.25, p<.001\right)$ and had sometimes felt like a form of spiritual service $\left(X^{2}(1)=62.30, p<.001\right)$. Along with these positive 
effects, therapists were also more likely than researchers to report that their work had sometimes depleted them emotionally $\left(X^{2}(1)=\right.$ 18.30, $\mathrm{p}<.001)$, and left them feeling helpless $\left(X^{2}(1)=32.10\right.$, $\mathrm{p}<$ .001). Overall, therapists felt that their work resulted in changes in their value systems more often than researchers $\left(X^{2}(1)=9.82, p=\right.$ .002). There were no statistically significant differences associated with theoretical orientation in this realm. 


\section{CHAPTER 4}

\section{DISCUSSION}

There was interest in looking at differential levels of job stress, as well as the personal problems and health concerns of both research psychologists and practitioners. A third area of interest was to look at possible differences in the techniques that the two groups used to relax.

In addition, four questions aimed at finding differences and similarities between the two groups were posed. Is there a difference between the two groups in happiness as a child or in childhood abuse? Is there any difference between the overall life satisfaction of therapists and researchers? Are there any differences in the experience of personal therapy between therapists and researchers? What impact does their work have on their personal lives? For each of the questions there was also interest in whether gender or level of experience contributed to any significant differences. 


\section{Job Stress}

What were the areas creating the most job stress for each group? While researchers' job stress centered around excessive teaching responsibilities and pressures associated with funding, therapists were most bothered by clients attempting suicide and showing resistance to treatment. These findings are consistent with previous research regarding job stress and therapists (Freudenberger, 1983; Elliott \& Guy, 1993; Hellman, Morrison, \& Abramawitz, 1987; Mahoney \& Fernandez-Alvarez, 1995). Research by Boice and Myers (1987) had suggested that researchers would experience higher levels of job-related stress, but this was not corroborated by this sample. Therapists in this study consistently endorsed job stressors in relatively greater numbers. As each group gained in experience there was a shift in concerns. For more experienced researchers, committee responsibilities, poor quality peer reviews, and excessive paperwork became more of a burden. More experienced therapists had greater problems with refusal of clients to pay for services, clients being seductive, and client death (not from suicide). For the sample of therapists this finding did not corroborate previous research (Farber \& Heifetz, 1981; Farber, 
1985) that indicated that psychotherapeutic work was more stressful for inexperienced therapists.

\section{Personal Problems and Health Concerns}

Are there differences in the personal problems and health concerns of the two groups? The two groups were similar in that financial security was at or near the top of the list for each. Findings by Boice and Myers (1987) that academicians experience health-related stress and mental health problems at a higher level than therapists was not corroborated by this study. Therapists reported more problems with anxiety and depression than did researchers. They also reported more concerns surrounding family problems and emotional exhaustion. This finding corroborated previous research examining therapists' concerns (Mahoney, 1997; Mahoney \& Fernandez-Alvarez, 1995). The only differences associated with level of experience were that more experienced therapists expressed more concern regarding poor health, while more experienced researchers expressed more concern about being overweight.

Concerns regarding alcohol use were consistently low throughout the study. Literature had suggested that males would report more concerns regarding their use of alcohol than would females (Elliott 
\& Guy 1993; Mahoney, 1997), but this was not corroborated by this sample.

\section{Relaxation Techniques}

How do researchers and therapists choose to relax? The two samples were very similar in this area. Top choices for relaxation were exercise/sports, watching movies/television, and pleasure reading. However, meditation/prayer, massage and stretching were more popular activities for therapists than researchers. These choices are generally consistent with previous research by Mahoney and Fernandez-Alvarez (1995).

\section{Childhood Happiness and Childhood Abuse}

Is there a difference between the two groups in childhood happiness? Based on previous research (Guy, 1987; Elliott \& Guy, 1993), it was predicted that there would be a significant difference in that therapists would report less happy childhoods than researchers. As predicted, therapists were less likely to report having had a happy childhood than were researchers. Further analysis however, appeared to indicate that the question of childhood happiness and childhood abuse are overlapping a great deal. When individuals who had reported childhood abuse were left out of 
the analysis, there was no difference between the two groups in reported childhood happiness.

On the issue of abuse as a child, therapists reported childhood abuse at a rate six times greater than the rate for researchers. It was predicted that females would report higher levels of sexual abuse (Elliott \& Guy, 1993). Although this study did not look solely at sexual abuse, females in the study were three times more likely than males to have reported childhood abuse.

\section{Life Satisfaction}

Is there a difference between the level of life satisfaction of therapists and researchers? It was predicted that therapists would report significantly greater degrees of life satisfaction than researchers. Therapists did report higher levels of life satisfaction as predicted. They also reported having good friends and liking where they lived more often than researchers. Both groups had the lowest level of satisfaction in the area concerned with liking their bodies.

\section{Personal Therapy}

Are there differences in the experience of personal therapy by researchers and therapists? Yes. As was expected three significant differences were found. Therapists were overwhelmingly (three 
times) more likely to have been in therapy than were researchers.

Once in therapy the average number of hours of therapy that therapists reported was six times greater than the average for researchers. They (therapists) had seen twice as many different mental health professionals as had researchers. The current number of therapists who had sought therapy $(75 \%)$ was substantially larger than was seen in the Deutsch (1985) study where only $47 \%$ had sought therapy at some time. It would seem that the number of therapists who have sought therapy may be on the rise as this higher number is much more in line with data collected more recently (Mahoney, 1997; Mahoney \& Fernandez-Alvarez, 1995). Impact of Work on Personal Life Are there differences in the impact of their work on their personal lives? This question is at the heart of this study. Research by Guy (1987) and Mahoney (1991) had suggested that there would be significant differences between the two groups in this area. As was predicted, therapists felt more strongly that their work had had an impact on their personal lives, mostly in positive ways. This array of positive benefits ranged from feeling their work had made them better as a person, increasing their self-awareness and accelerating their psychological development, to feeling they 
were more tolerant of ambiguity. They also felt that they had learned to better detach from their feelings. In addition, therapists reported appreciating human relationships, respecting individual differences, and enjoying life more than their research peers. At the same time, there were negative correlates of psychotherapeutic work. Therapists were more likely to feel that their work had left them feeling helpless and emotionally depleted. It appears that they were able to focus more on the positive aspects of their career as they expressed the feeling that their work felt like a form of spiritual service and acknowledged that it had changed their value systems. This corroborates previous research where therapists focused more on the positive benefits and saw their careers as gratifying (Farber, 1983; Farber, 1985; Mahoney \& FernandezAlvarez, 1995; Norcross \& Prochaska, 1982). Based on literature (Guy, 1987; Mahoney, 1991), it had been hypothesized that as level of experience increased the positive benefits would also increase, this was not supported by this sampling. As therapists gained in experience they indicated a negative correlation with increasing self-awareness. 


\section{Conclusion}

The present data suggest the following generalizations.

Therapists go into therapy at a far greater rate than researchers.

The imperative "Heal thyself" is taken to heart by this group.

Psychologically speaking, therapists reported that their work

affected their lives to a much greater extent than did their

counterparts in research. The benefits seemed to be mostly

positive, accelerating their overall psychological development and

increasing their joy in their experiences of life. Although their

early lives were not as happy, therapists reported a greater overall

life satisfaction than did researchers. The positive benefits of

being a therapist do seem to outweigh the negative. Therapists also

seemed to be experiencing an accelerated psychological development

that was greater than that of their research counterparts.

The findings of this particular project add to the literature on the personal lives of the therapist which is sorely in need of further investigation. It represents what may be one of the first if not the first parallel survey of psychologists not involved in therapeutic activities (i.e., research psychologists). It provides at least preliminary evidence for comparison that may eventually touch on issues not only on the impact of research versus therapy on the 
personal lives of the professionals involved, but also potentially on factors that may have contributed to their choice to pursue primarily research or therapeutic services. The comparisons between the therapist group and the researcher group are provocative in suggesting that there are substantially greater increases or self-reported increases in accelerated psychological development, appreciation for human relationships, respect of individual differences and capacity to enjoy life, to name a few.

One of the findings from the present study that deserves replication and further investigation is the possible role of early childhood abuse in influencing career decisions and motivations of psychotherapists. It would be important for future research to look into individual's awareness of the role their early childhood experiences may have played in their career choice and the possibility that those experiences might serve as both strengths and weaknesses in delivering services to others.

The present findings suggest the importance of two themes in graduate training. The first is the importance of self-awareness in the preparation of service providers in psychology. Dealing with the reality of the stresses involved in a career in psychotherapy is the second theme. The present study suggests that there are stresses 
involved in both the research and the practical side of psychology. However the stresses involved with being a therapist tend to be more crisis oriented and emotional such as expressed anger. Given that there are stresses in both specializations and that the stresses and complexities of being a therapist are apparent not only in these findings but in prior surveys (Mahoney \& Fernandez-Alvarez, 1995), there is a need to emphasize the importance of self-care among therapists particularly at the beginning stages in their professional apprenticeship.

As with all investigations, the current study had limitations that placed constraints on interpretations that could be made from its data. To begin with, this survey was based on a self-report instrument and all the problems associated with self-report and self-awareness of respondents, (i.e., bias, faking, good or bad response sets, etc.) apply to the evidence presented here (Denzin \& Lincoln, 1994). The instrument used posed questions in a format that necessarily limited the range of responses. In addition, this was a convenience sample drawn from a series of conferences and psychological meetings and there may be variables associated not only with that confluence but with those who were willing to participate in this project. Because this project was an exploratory 
study, these limitations were considered warranted in the interest of providing further information to clarify and refine questions currently being asked. In addition, no attempt was made to equal gender numbers within each sample and this makes results, when looking at gender questions, suspect. One should, therefore, be cautious in interpreting these results and the inferences that may be drawn from them.

Research aimed at clarifying and refining this study would be helpful. A lorigitudinal study beginning in the early stages of therapists' and researchers' college careers would be a good method to continue this line of research. In addition, surveying a population in a field outside of pscyhology (i.e., business) would provide additional data for comparisons regarding work impact on an individual's personal life. There is a need to develop a new checklist of job stressors experienced by research psychologists. The checklist used in this study was exploratory in nature and is in need of refinement. Developing a new checklist by allowing research psychologists to list their own stressors could provide a more complete picture of the stressors they experience at work.

Psychologists are human beings and in the present data the stresses and personal concerns of the respondents are quite 
apparent. In fact it appears that therapists at all stages in their lives and careers are still dealing with personal concerns. That finding might encourage a sensitivity to unrealistic expectations that trainees might develop about being totally finished with their own personal problems before they are ready to do therapy. Contrary to early literature which emphasized the unhappiness and possible impairment of therapists, the present research contributes to a more humane picture of therapists as individuals who are struggling with their own personal concerns and life situations. These individuals are clearly capable of learning not only from their own experiences but from the experiences of their clients in ways that serve their current and future clients in the best possible way. 


\section{APPENDIX A}

\section{QUESTIONNAIRES}




\section{RESEARCH PSYCHOLOGIST PERSONAL LIFE QUESTIONNAIRE}

Dear Research Psychologist:

My name is JoAnn Radeke. I am currently a clinical doctoral candidate at the University of North Texas and am conducting research for my dissertation. The attached survey is intended to gather information regarding the personal life satisfactions of research psychologists and psychotherapists. My study is entitled Comparing the Personal Life of Psychotherapists and Research Psychologists and will examine the stresses, relaxation strategies, and general experiences of each group.

$\mathrm{Be}$ assured that all questionnaires are STRICTLY CONFIDENTIAL. Your questionnaire is not identifiable as such. I am interested in the answers of all respondents taken in groups rather than in the answers of any one respondent. Results will be reported in general statistical form.It is understood that reading this letter and completing this survey constitutes informed consent.

Participation in this study is completely voluntary and if you choose not to participate no benefits will be lost. If you have any further questions, you may contact me at (214) 932-3633.

Thank you for your help,

JoAnn Radeke, B.A.

Clinical Doctoral Candidate

University of North Texas

This project has been reviewed and approved by University of North Texas Institutional Review Board (817) 565-3940. 
Thank you for your participation in this study. Your responses are completely voluntary and anonymous. If a question is unclear or too personal, do not answer it. Feel free to write in the margins and/or to elaborate. Thank you again.

1. Theoretical Orientation: Original Training:

Current:

2. Years as a research psychologist?

3. Specialization(s)?

4. Primary employment? government agency private/group practice other:

5. Average hours per week doing ...

$\begin{array}{lll}\text { direct data collection } & \text { research supervision } & \text { professional reading } \\ \text { writing research reports } & \text { _teaching } & \text { professional writing } \\ \text { non-research paperwork } & \text { research } & \text { recreation, rest, self-care }\end{array}$

6. Below are descriptions of experiences in research. Please check those you have experienced.

poor quality peer reviews

difficulties with ethics review boards

pressures associated with funding

concerns about job security

bureaucratic problems

excessive teaching responsibilities

lack of motivation

lack of time for personal life

feeling overwhelmed by size of literature

problems with administrators

problems with experimental subjects

problems getting research published

computer problems

excessive paperwork

excessive committee responsibilities

lack of new ideas

feeling overwhelmed by pace of change restrictions on freedom of inquiry

7. Reviewing the iterrs you checked above in \#6, please rank $(1,2,3)$ the 3 most difficult categories for you. Let "1" mean "most difficult," "2 = second most difficult," etc. Mark your ranking next to your checkmark.

8. As to my personal tife ... (check all that apply) ...

I am happy I am healthy

I like myself I like where I live I have good friends

I had a happy childhood I am a complex person I am a private person I was abused as a child I lost a parent or sibling while I was a child

9. I currently live ... (check all that apply)... alone _ with a spouse or life partner ___. with child(ren) with parents or grandparents with sibling(s) with friends

12. Below are a variety of personal and health concerns. Please check any that have ever been concerns for you (at any point in your life).

poor heaith depression poor anger control low self-confidence sleep problems sexual functioning anxiety alcohol use problems trusting people financial security being overweight low self-esteem feelings of loneliness 
-_ relationship problems

emotional exhaustion

family problems

drug use

shyness

chronic pain

schizophrenia

anorexia/bulimia

obsessions/compulsions

13. Reviewing the items you checked above in $\# 12$, please rank $(1,2,3)$ the 3 most important concerns for you during the past year. Let "1" be the "most important," etc. Mark your ranking next to your checkmark.

14. Below are questions about your experience(s) of being a client in psychotherapy. If you have never been a client in psychotherapy, go to question \#15.

How many total hours of personal (individual) therapy have you had?

How many different therapists have you seen as a client?

To what extent do you agree with each of the following statements?

My personal therapy has been a valuable experience.

I have had negative experiences as a client.

Disagree

I have been embarrassed about needing personal therapy.

The financial cost of personal therapy has been a problem.

$\begin{array}{llll}1 & 2 & 3 & 4 \\ 1 & 2 & 3 & 4 \\ 1 & 2 & 3 & 4 \\ 1 & 2 & 3 & 4\end{array}$

15. In reference to the effects of your work as a research psychologist on your personal life, to what extent would you agree with each of the following statements?

"My work as a research psychologist ... .

has made me a better person.

has caused me to physically age more rapidly.

has not had any effect on my personal life.

has sometimes depleted me emotionally.

has increased my self-awareness.

has accelerated my psychological development.

has caused me to be more cynical about life.

has increased my appreciation for human relationships.

$\begin{array}{cccc}\text { Disagree } & & & \text { Agree } \\ 1 & 2 & 3 & 4 \\ 1 & 2 & 3 & 4 \\ 1 & 2 & 3 & 4 \\ 1 & 2 & 3 & 4 \\ 1 & 2 & 3 & 4 \\ 1 & 2 & 3 & 4 \\ 1 & 2 & 3 & 4 \\ 1 & 2 & 3 & 4 \\ 1 & 2 & 3 & 4 \\ 1 & 2 & 3 & 4 \\ 1 & 2 & 3 & 4 \\ 1 & 2 & 3 & 4 \\ 1 & 2 & 3 & 4 \\ 1 & 2 & 3 & 4 \\ 1 & 2 & 3 & 4 \\ 1 & 2 & 3 & 4 \\ 1 & 2 & 3 & 4 \\ 1 & 2 & 3 & 4 \\ 1 & 2 & 3 & 4 \\ 1 & 2 & 3 & 4\end{array}$

has made me more respectful of individual differences.

has made me more pessimistic about human nature.

has made me a wiser person.

has sometimes left me feeling helpless.

has increased my capacity to enjoy life.

has sometimes felt like a form of spiritual service.

has sometimes caused me to doubt the value of research.

has left me with vivid memories of satisfactions.

has left me with vivid memories of disappointments.

has increased my capacity to detach from my feelings.

has made me more tolerant of ambiguity.

has resulted in changes in my value system.

16. How do you seek relaxation or recreation? (Check all that apply)

exercise / sports

meditation / prayer

dancing

movies / television

hobbies music massage travel

other: pleasure reading naps

stretching

socializing with friends

walking 
17. Reviewing the activities you checked above in question 16 , please rank $(1,2,3)$ your first, second, and third most frequent choices. Mark your ranking next to your checkmark.

18. What is your age ?

19. What is your gender?

20. What is your Ethnic identity?

21. What is your current religion? (if "none," please indicate) 


\section{PSYCHOTHERAPIST PERSONAL LIFE QUESTIONNAIRE}

\section{Dear Psychotheriapist:}

My name is JoAnn Radeke. I am currently a clinical doctoral candidate at the University of North Texas and am conducting research for my dissertation. The attached survey is intended to gather information regarding the personal life satisfactions of research psychologists and psychotherapists. The study is entitled Comparing the Personal Life of Psychotherapists and Research Psychologists and will examine the stresses, relaxation strategies, and general experiences of each group.

Be assured that all questionnaires are STRICTLY CONFIDENTIAL. Your questionnaire is not identifiable as such. I am interested in the answers of all respondents taken in groups rather than in the answers of any one respondent. Results will be reported in general statistical form.It is understood that reading this letter and completing this survey constitutes informed consent.

Participation in this study is completely voluntary and if you choose not to participate no benefits will be lost. If you have any further questions, you may contact me at (214) 932-3633.

Thank you for your help,

JoAnn Radeke, B.A.

Clinical Doctoral Candidate University of North Texas 
Thank you for your participation in this study. Your responses are completely voluntary and anonymous. If a question is unclear or too personal, do not answer it. Feel free to write in the margins and/or to elaborate. Thank you again.

1. Theoretical Orientation: Original Training:

Current:

2. Years as a psychotherapist?

3. Specialization(s)?

4. Primary employment? government agency private/group practice other:

5. Average hours per week doing ...

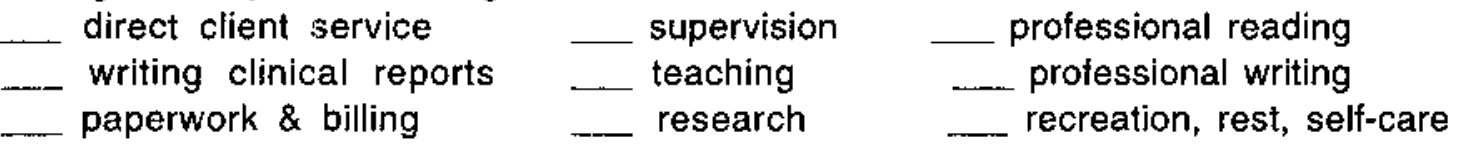

6. Below are descriptions of experiences with clients. Please check those you have experienced.

clients being angry

clients showing resistance

hallucinations by clients

suicide attempts by clients

clients phoning me excessively

clients being physically violent

hospitalizing a client

death of a client (but not by suicide)

clients refusing to pay for services clients being seductive paranoid behavior by clients clients becoming dependent on me multiple personality clients panic attacks in clients death of a client from suicide clients suing me premature termination by clients clients offering me inappropriate gifts

7. Reviewing the items you checked above in \#6, please rank $(1,2,3)$ the 3 most difficult categories for you. Let "1" mean "most difficult," "2 = second most difficult," etc. Mark your ranking next to your checkmark.

8. As to my personal life ... (check all that apply) ...

I am happy 1 am healthy

I like myself I had a happy childhood I I like where I live _ I have good friends
I like my body I I am a complex person _ I am a private person I had a happy childhood I I like where I live I I have good friends
I like my body I I am a complex person _ I am a private person I was abused as a child I lost a parent or sibling while I was a child

9. I currently live ... (check all that apply) ... alone __ with a spouse or life partner ___ with child(ren) with parents or grandparents __ with sibling(s) __ with friends

12. Below are a variety of personal and health concerns. Please check any that have ever been concerns for you (at any point in your life).

poor health

depression

poor anger control

low self-confidence sleep probiems sexual functioning problems trusting people financial security

anxiety alcohol use being overweight low self-esteem feelings of loneliness 
relationship problems

family problems

drug use

emotional exhaustion

chronic pain

shyness

schizophrenia

anorexia/bulimia

13. Reviewing the items you checked above in $\# 12$, please rank $(1,2,3)$ the 3 most important concerns for you during the past year. Let " 1 " be the "most important," etc. Mark your ranking next to your checkmark.

14. Below are questions about your experience(s) of being a client in psychotherapy. If you have never been a client in psychotherapy, go to question \#15.

How many total hours of personal (individual) therapy have you had?

How many different therapists have you seen as a client?

To what extent do you agree with each of the following statements?

My personal therapy has been a valuable experience.

I have had negative experiences as a client.

I have been embarrassed about needing personal therapy.

The financial cost of personal therapy has been a problem.

\begin{tabular}{cccc}
\multicolumn{3}{c}{ Disagree } & Agree \\
1 & 2 & 3 & 4 \\
1 & 2 & 3 & 4 \\
1 & 2 & 3 & 4 \\
1 & 2 & 3 & 4
\end{tabular}

15. In reference to the effects of your work as a psychotherapist on your personal life, to what extent would you agree with each of the following statements? "My work

has made me a better prerson.

has caused me to physically age more rapidly.

has not had any effect on my personal life.

has sometimes depleted me emotionally.

has increased my self-awareness.

has accelerated my psychological development.

has caused me to be more cynical about life.

has increased my appreciation for human relationships.

Disagree

has made me more respectful of individual differences.

has made me more pessimistic about human nature.

has made me a wiser person.

has sometimes left me feeling helpless.

has increased my capacity to enjoy life.

has sometimes felt like a form of spiritual service.

has sometimes caused me to doubt the value of psychotherapy.

has left me with vivid memories of clients' tragedies.

has left me with vivid memories of clients' triumphs.

has increased my capacity to detach from my feelings.

has made me more tolerant of ambiguity.

has resulted in changes in my value system.

$\begin{array}{cccc}1 & 2 & 3 & 4 \\ 1 & 2 & 3 & 4 \\ 1 & 2 & 3 & 4 \\ 1 & 2 & 3 & 4 \\ 1 & 2 & 3 & 4 \\ 1 & 2 & 3 & 4 \\ 1 & 2 & 3 & 4 \\ 1 & 2 & 3 & 4 \\ 1 & 2 & 3 & 4 \\ 1 & 2 & 3 & 4 \\ 1 & 2 & 3 & 4 \\ 1 & 2 & 3 & 4 \\ 1 & 2 & 3 & 4 \\ 1 & 2 & 3 & 4 \\ 1 & 2 & 3 & 4 \\ 1 & 2 & 3 & 4 \\ 1 & 2 & 3 & 4 \\ 1 & 2 & 3 & 4 \\ 1 & 2 & 3 & 4 \\ 1 & 2 & 3 & 4\end{array}$

16. How do you seek relaxation or recreation? (Check all that apply)

exercise / sports

meditation / prayer dancing

movies / television

hobbies music massage travel

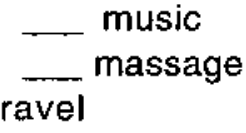
socializing with triends pleasure reading naps

stretching

other: walking 
17. Reviewing the activities you checked above in question 16 , please rank $(1,2,3)$ your first, second, and third most frequent choices. Mark your ranking next to your checkmark.

18. What is your age? 19. What is your gender?

20. What is your ethnic identity?

21. What is your current religion? (if "none," please indicate) 
APPENDIX B

TABLES 
Table 1

Researcher Current Theoretical Orientation

\begin{tabular}{lrr}
\hline Orientation & Frequency & $\%$ \\
\hline & & \\
Experimental/Research & 36 & 24.6 \\
Cognitive & 14 & 9.6 \\
Integrative/Eclectic & 11 & 7.5 \\
Behavioral & 8 & 5.5 \\
Social & 7 & 4.8 \\
Cognitive /Behavioral & 6 & 4.1 \\
Industrial/Organizational & 5 & 3.4 \\
Psychodynamic & 4 & 2.7 \\
Social Learning & 2 & 1.4 \\
Clinical & 2 & 1.4 \\
Physiological & 2 & 1.4 \\
Developmental & 2 & 1.4 \\
Counseling & 2 & 1.4 \\
Learning & 1 & .7 \\
Missing & 44 & 30.1 \\
& & \\
\hline
\end{tabular}


Table 2

Therapist Current Theoretical Orientation

\begin{tabular}{lrr}
\hline & & \\
Orientation & Frequency & $\%$ \\
\hline & 38 & 29.2 \\
Integrative/Eclectic & 23 & 17.7 \\
Psychodynamic & 16 & 12.3 \\
Cognitive/Behavioral & 9 & 6.9 \\
Systems & 6 & 4.6 \\
Other & 3 & 2.3 \\
Behavioral & 3 & 2.3 \\
Cognitive & 2 & 1.5 \\
Humanistic & 1 & .8 \\
Social Learning & 1 & .8 \\
Brief & 1 & .8 \\
Private Practice & 1 & .8 \\
Clinical & 26 & 20.0 \\
Missing & & \\
\hline
\end{tabular}


Table 3

Researcher Rankings of Job Stressors

Stressor

Frequency

$\%$

Excessive teaching responsibilities

45

30.8

Pressures associated with funding

42

28.8

Lack of time for personal life

40

27.4

Bureaucratic problems

39

26.8

Excessive cornmittee responsibilities

33

22.6

Excessive paperwork

30

20.5

Computer problems

24

16.5

Problems getting research published

22

15.0

Feeling overwhelmed by size of literature

22

15.0

Problems with administrators

20

13.7

Concerns about job security

19

13.0

Poor quality peer reviews

19

13.0

Problems with experimental subjects

17

11.6

Lack of motivation

11

7.5

Difficulties with ethics review boards

Lack of new ideas

10

6.8

Feeling overwhelmed by pace of change

Restrictions on freedom of inquiry

3

2.1

$2 \quad 1.4$

2

1.4

Note. Frequency and percent are calculated based on number of times an item was ranked 1,2 , or 3 . 
Table 4

Therapist Rankings of Job_Stressors

Stressor

Frequency $\%$

Suicide attempts by clients

57

43.9

Clients showing resistance

39

30.1

Clients being angry

33

25.4

Premature termination by clients

28

21.5

Paranoid behavior by clients

25

19.3

Clients becoming dependent on me

25

19.3

Hospitalizing a client

23

17.7

Clients being physically violent

22

17.0

Death of a client (but not by suicide)

20

15.3

Clients refusing to pay for services

18

13.9

Clients phoning me excessively

17

Hallucinations by clients

17

13.0

Multiple personality clients

17

13.0

Death of a client from suicide

Clients being seductive

14

13.0

Panic attacks in a client

12

10.8

Clients offering me inappropriate gifts

10

9.1

3

7.7

Clients suing me

2

2.4

1.6

Note. Frequency and percent are calculated based on number of times an item was ranked 1,2 , or 3 . 
Table 5

Researcher Rankings of Personal Problems and Health Concerns

Problem or Health Concern

Frequency

$\%$

Financial Security

Relationship Problems

Sleep problems

Low self-confidence

Shyness

Anxiety

Being overweight

Depression

Family problems

Feelings of loneliness

Poor health

Low self-esteem

Poor anger control

Alcohol use

Drug use

Chronic pain

Sexual functioning

Problems trusting people

Obsessions/compulsions

Anorexia/bulimia

Schizophrenia
29

27

26

22

21

18

15

14

14

12

11

10

8

5

4

4

2

2

1

0

0
19.9

18.5

17.8

15.0

14.4

12.2

10.3

9.6

9.6

8.2

7.6

5.5

6.2

3.5

2.8

2.8

1.4

1.4

.7

0

0

Note. Frequency and percent are calculated based on number of times an item was ranked 1,2 , or 3 . 
Table 6

Therapist Rankings of Personal Problems and Health Concerns

Problem or Health Concern

Frequency $\%$

Emotional exhaustion

36

27.7

Financial security

31

23.9

Anxiety

31

23.9

Being overweight

26

20.0

Depression

24

18.5

Low self-confidence

24

18.5

Sleep problems

24

18.5

Relationship problems

22

16.9

Family problems

13

Poor health

9

10.0

Shyness

5

6.9

Sexual functioning

3

3.8

Alcohol use

2.4

Poor anger control

2

1.6

Problems trusting people

2

1.6

Drug use

Anorexia/bulimia

1

.8

1

.8

Obsessions/compulsions

Schizophrenia

1

1

.8

.8

0

0

Note. Frequency and percent are calculated based on number of times an item was ranked 1,2 , or 3 . 
Table 7

Researcher Rankings of Forms of Relaxation

\begin{tabular}{lcc} 
Activity & Frequency & $\%$ \\
\hline & & \\
Exercise/sports & 67 & 47.2 \\
Movies/television & 54 & 38.1 \\
Pleasure reading & 48 & 33.9 \\
Music & 41 & 28.9 \\
Socializing with friends & 35 & 24.7 \\
Travel & 28 & 19.7 \\
Walking & 26 & 18.3 \\
Hobbies & 19 & 13.3 \\
Meditation/prayer & 16 & 11.2 \\
Naps & 13 & 9.1 \\
Other & 11 & 7.7 \\
Stretching & 1 & .7 \\
Massage & 1 & .7 \\
\end{tabular}

Note. Frequency and percent are calculated based on number of times an item was ranked 1,2 , or 3 . 
Table 8

Therapist Rankings of Forms of Relaxation

\begin{tabular}{lcc} 
Activity & Frequency & $\%$ \\
\hline & & \\
Exercise/sports & 55 & 43.0 \\
Movies/television & 49 & 38.3 \\
Pleasure reading & 45 & 35.2 \\
Socializing with friends & 41 & 32.1 \\
Meditation/prayer & 31 & 24.2 \\
Walking & 19 & 14.8 \\
Hobbies & 18 & 14.1 \\
Other & 18 & 14.1 \\
Travel & 15 & 11.7 \\
Massage & 4 & 3.2 \\
Naps & 4 & 3.2 \\
Dancing & 3 & 2.4 \\
Stretching & 0 & 0 \\
\end{tabular}

Note. Frequency and percent are calculated based on number of times an item was ranked 1,2 , or 3. 
Table 9

Researcher Life Satisfaction Variables

\begin{tabular}{lrr}
\hline & & \\
Variable & Frequency & $\%$ \\
& & \\
& & \\
I am happy* & 129 & 88.4 \\
I am healthy* & 127 & 87.0 \\
I like myself* & 132 & 90.4 \\
I like my work* & 135 & 92.5 \\
I had a happy childhood & 111 & 76.0 \\
I like where I live* & 98 & 67.1 \\
I have good friends* & 118 & 80.8 \\
I like my body* & 90 & 61.6 \\
I am a complex person & 90 & 61.6 \\
I am a private person & 85 & 58.2 \\
I was abused as a child & 4 & 8.9 \\
\end{tabular}

Note. * Items comprise the variable called "Life Satisfaction" 
Table 10

Therapist Life Satisfaction Variables

$\begin{array}{ll}\text { Variable } & \text { Frequency } \%\end{array}$

I am happy*

I am healthy*

I like myself*

I like my work*

I had a happy childhood

I like where I live*

I have good friends*

I like my body*

I am a complex person

I am a private person

I was abused as a child

I lost a parent or sibling while I was a child
$119 \quad 91.5$

$122 \quad 93.8$

12394.6

$119 \quad 91.5$

$\begin{array}{ll}79 & 60.8\end{array}$

$108 \quad 83.1$

$119 \quad 91.5$

$85 \quad 65.4$

$86 \quad 66.2$

$77 \quad 59.2$

$24 \quad 18.5$

$19 \quad 14.6$

Note. "Items comprise the variable called "Life Satisfaction" 
Table 11

Researcher Reports of Work Impact on Personal Life

Impact

Made me a wiser person

Made me a better person

Made me more respectful of individual differences Increased my self-awareness

Accelerated my psychological development

Left me with vivid memories of satisfactions

Made me more tolerant of ambiguity

Increased my appreciation for human relationships

Sometimes depleted me emotionally

Increased my capacity to enjoy life

Resulted in changes in my value system

Sometimes caused me to doubt the value of research

Not had any effect on my personal life

Left me with vivid memories of disappointments

Caused me to be more cynical about life

Sometimes left me feeling helpless

Made me more pessimistic about human nature

Sometimes felt like a form of spiritual service Increased my capacity to detach from my feelings Caused me to physically age more rapidly
Frequency $\%$

$108 \quad 80.8$

$114 \quad 78.1$

$101 \quad 69.1$

$100 \quad 68.5$

$100 \quad 68.5$

$91 \quad 62.3$

$84 \quad 57.5$

$82 \quad 56.2$

$77 \quad 52.8$

$\begin{array}{ll}74 & 50.7\end{array}$

$55 \quad 37.7$

$53 \quad 36.6$

$47 \quad 32.2$

$45 \quad 30.8$

$39 \quad 26.7$

$38 \quad 26.0$

$37 \quad 25.4$

$36 \quad 24.6$

$34 \quad 23.2$

$\begin{array}{ll}29 & 19.8\end{array}$ 
Table 12

Therapist Reports of Work Impact on Personal Life

Impact

Frequency

$\%$

Made me a better person

122

93.9

Made me more respectful of individual differences 122

93.9

Increased my self-awareness

120

92.3

Made me a wiser person

120

Increased my appreciation for human relationships 117

92.3

Accelerated my psychological development

116

90.0

Made me more tolerant of ambiguity

105

89.2

Sometimes depleted me emotionally

104

Increased my capacity to enjoy life

97

80.8

80.0

Sometimes felt like a form of spiritual service

96

74.6

Left me with vivid memories of clients' triumphs

73.8

Sometimes left me feeling helpless

95

73.0

Resulted in changes in my value system

80

79

Increased my capacity to detach from my feelings 73

Sometimes caused me to doubt the value of therapy 51

61.5

60.7

Left me with vivid memories of clients' tragedies

50

Caused me to be more cynical about life

35

Made me more pessimistic about human nature

32

Caused me to physically age more rapidly

56.1

39.3

38.5

27.0

Not had any effect on my personal life

13

24.7

13.2

10.0 


\section{REFERENCES}

Bergin, A. E. \& Garfield, S. L. (1994). Handbook of Psychotherapy and Behavior Change (4th ed.). New York: John Wiley \& Sons.

Boice, R., \& Myers, P. E. (1987). Which setting is happier, academe or private practice? Professional Psychology: Research and Practice. 18, 526-529.

Denzin. N. K., \& Lincoln. Y. S. (Eds.) (1994). Handbook of Qualitative Research. Sage Publications.

Deutsch, C. J. (1985). A survey of therapists' personal problems and treatment. Professional Psychology: Research and Practice, 16, (2), 305-315.

Elliott, D. M., \& Guy, J. D. (1993). Mental health professionals versus non-mental-health professionals: Childhood trauma and adult functioning. Professional Psychology: Research and Practice. 24, 83-90.

Farber, B. A. (1985). Clinical psychologists' perceptions of psychotherapeutic work. Clinical Psychologist, 38, 10-13. 
Farber, B. A. (1983). The effects of psychotherapeutic practice upon the psychotherapists. Psychotherapy: Theory, Research and Practice, 20, 174-182.

Farber, B. A., \& Heifetz, L. (1982). The process and dimensions of burnout in psychotherapists. Professional Psychology 13, 293-302.

Freud, S. (1964). Analysis terminable and interminable. In J. Strachey (Ed. And Trans.), The standard edition of the complete works of Sigmund Freud (volume 23). London: Hogarth, (Originally published, 1937).

Freudenberger, H. J. (1983). Hazards of psychotherapeutic practice. Psychotherapy in Private Practice, 1, 83-89.

Garfield S. L., \& Bergin, A. E. (1986). Handbook of psychotherapy and behavior change: An empirical analysis. New York: John Wiley.

Garfield, S. L., \& Kurtz, R. M. (1974). A survey of clinical psychologists: Characteristics, activities and orientations. The Clinical Psychologist, 28, 7-10.

Garfield, S. L., \& Kurtz, R. M. (1975a). Training and career satisfaction among clinical psychologists. The Clinical Psychologist. 28, 6-9. 
Garfield, S. L., \& Kurtz, R. M. (1975b). The clinical psychologists: A survey of selected attitudes and views. The Clinical Psychologist, $28,4-7$.

Garfield, S. L., \& Kurtz, R. M. (1976). Personal therapy for the psychotherapist: Some findings and issues. Psychotherapy: Theory, Research and Practice. 13, 188-192.

Guy, J. D. (1987). The personal life of the psychotherapist. New York: John Wiley \& Sons.

Hellman, I. D., \& Morrison, T. L. (1987). Practice setting and type of caseload as factors in psychotherapist stress. Psychotherapy, 24, 427-433.

Henry, W., Sims, J., \& Spray, S. L. (1971). The fifth profession. San Francisco: Jossey-Bass.

Henry, W., Sims, J., \& Spray, S. L. (1973). Public and private lives of psychotherapists. San Francisco: Jossey-Bass.

Kelly, E. L. (1961). Clinical psychology - 1960. Report of survey of findings. Division of Clinical Psychology of the American Psychological Association, 14, 1-11.

Kottler, J. A. (1986). On being a therapist. San Francisco: Jossey Bass. 
Mahoney, M. J. (1991). Human change processes. New York: Basic Books.

Mahoney, M. J. (1997). Psychotherapists' personal problems and self-care patterns. Professional Psychology: Research and Practice, $\underline{28}(1), \quad 14-16$

Mahoney, M. J., \& Fernandez-Alvarez, H. (1995). The personal life of the psychotherapist. Manuscript submitted for publication.

Norcross, J. C., \& Prochaska, J. O. (1982a). A national survey of clinical psychologists: Characteristics and activities. Clinical Psychologist, 35(2), 1-8.

Norcross, J. C., \& Prochaska, J. O. (1982b). A national survey of clinical psychologists: Characteristics and activities. Clinical Psychologist, 35(3), 1-6.

Norcross, J. C., \& Prochaska, J. O. (1982c). A national survey of clinical psychologists: Characteristics and activities. Clinical Psychologist, 35(4), 1-6.

Prochaska, J. O., \& Norcross, J. C. (1983). Contemporary Psychotherapists: A national survey of characteristics, practices, orientations, and attitudes. Psychotherapy: Theory, Research and Practice, 20(2), 161-173. 
Sarason, S. B. (1981). Psychology misdirected. New York: Free Press.

Thoreson, R. W., Miller, M., \& Krauskopf, D. J. (1989). The distressed psychologist: Prevalence and treatment considerations. Professional Psychology: Research and Practice, 20, 153-158. 